\author{
Military Technical College \\ Cairo, Egypt
}

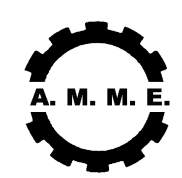

$12^{\text {th }}$ International Conference

on Applied Mechanics and

Mechanical Engineering (AMME)

\title{
DIESEL ENGINE MISFIRE DETECTION UTILIZING TIME- FREQUENCY ANALYSIS OF MEASURED ENGINE VIBRATION
}

\author{
Badawi $^{*}$ A. B., A. Elmaihy ${ }^{* *}$, Samy ${ }^{* * *}$ A. S., Shahin ${ }^{* * *}$, M. A. and \\ Mohamed $^{* * * *}$ K. I.
}

\begin{abstract}
This paper describes the detection of diesel engine cylinder misfire utilizing the engine vibration measurements. The proposed technique depends on time-frequency analysis (TFA) of the measured engine surface vibration. The combustion Induced vibration and noise of engine is mathematically modeled and the vibration signals are simulated for fired and misfired engine. Both simulated and measured vibration signals for fire and misfire are analyzed by fast Fourier transform (FFT) in frequency domain to identify the signals' frequencies. Then, they are analyzed in timefrequency plane. To investigate the engine fire and misfire according to firing order of the engine cylinders, the time-frequency plane is converted to the corresponding crank angle-frequency one. From crank angle-frequency analysis of the engine vibration the engine misfire is detected from the measured vibration signal as well as from the simulated one. The experimental results show that the engine misfire can be detected by time frequency analysis of measurd enginesurface vibration.
\end{abstract}

\section{KEYWORDS}

Diesel engine, engine fire, engine misfire, time-frequency analysis and vibration.

\footnotetext{
*PhD Postgraduate candidate, Dept. of Mech. Power and Energy, Military Technical College, Cairo, Egypt.

${ }^{* *}$ Egyptian Armed Forces.

Ek** Egyptian Armed Forces.

Assistant Prof., Faculty of Engineering, Modern University of Engineering and Technology, Cairo, Egypt

${ }^{*}$ Egyptian Armed Forces.
} 


\section{NOMENCLATURE}

\begin{tabular}{|c|c|}
\hline ATDC & After topd ead centre \\
\hline C & $\begin{array}{l}\text { Bottom dead centre } \\
\text { Damping constant }\end{array}$ \\
\hline CA & Crank Angle \\
\hline CARB & California air resources board \\
\hline CMEP & Cylinder mean effective pressure \\
\hline$e_{p, r}(t)$ & Discrete inverse short time Fourier transform basis function \\
\hline$\tilde{e}_{p, r}^{*}(t)$ & Discrete short time Fourier transform basis function \\
\hline$e_{\tau, f}(t)$ & Continuous short time Fourier transform basis function in \\
\hline$\tilde{e}_{\tau, f}^{*}(t)$ & Continuous inverse short time Fourier transform basis function \\
\hline$F(t)$ & Force signal \\
\hline FFT & Fast Fourier transform \\
\hline FT & Fourier Transform \\
\hline $\mathrm{F}_{\mathrm{g}}$ & Cylinder Gas force \\
\hline $\mathrm{F}_{\mathrm{i}}$ & Inertia force of piston and connecting rod reciprocating part. \\
\hline$f$ & Frequency \\
\hline IMEP & Indicated mean effective pressure \\
\hline $\mathrm{k}$ & Stiffness constant \\
\hline $\mathrm{m}$ & Mass \\
\hline $\mathrm{n}$ & Engine speed \\
\hline Q & Reversible lateral force \\
\hline PCA & Principal component analysis \\
\hline STFT & Short time Fourier transform \\
\hline $\mathrm{T}$ & time \\
\hline TFA & Time-frequency analysis \\
\hline$X(f)$ & Fast Fourier transform of the signal $\mathrm{x}(\mathrm{t})$ \\
\hline$X[p, r]$ & Discrete time-frequency expansion \\
\hline$X(\tau, f)$ & Continuous time-frequency expansion \\
\hline$x(t)$ & Continuous time signal. \\
\hline$\dot{x}$ & Mass velocity \\
\hline$\ddot{x}$ & Mass acceleration \\
\hline w & Window \\
\hline$\tau$ & Time \\
\hline$\omega$ & Force Frequency \\
\hline$\omega_{\mathrm{n}}$ & Natural frequency \\
\hline$\omega_{\mathrm{d}}$ & Damped natural frequency \\
\hline$\zeta$ & Damping factor \\
\hline
\end{tabular}




\section{INTRODUCTION}

The goal of this paper is to detect misfire in a multi-cylinder diesel engine by the timefrequency analysis of vibration signal instead of pressure transducers. According to California Air Resources Board (CARB) regulations, engine misfire means, "lack of combustion in cylinder due to absence of spark, poor fuel metering, poor compression, or any other cause", [1]. The regulations require that the vehicle's engine diagnostic system monitors misfire continuously. This concern is due to the fact that, even with a small number of misfiring cycles, engine performance degrades, hydrocarbon emissions increase, and drivability will suffer [2].

Heywood [3] classified engine cycles in three groups: i) slow-burn cycle, with indicated mean effective pressure (IMEP) between 85-46 percent of the mean value, where combustion is completed but ends after $80^{\circ}$ ATDC; ii) partial-burn cycles, where IMEP is less than 46 percent of the mean value; iii) misfiring cycles, where the IMEP is less than zero. Another Classification was given by Martin et. al. [4]: i) cycles having IMEP less than or equal zero which represent complete misfire; ii) cycles with large IMEP variations; iii) cycles with normal IMEP.

The following methods of misfire detection were mentioned in references [1-2] and [5] and can be summarized as:

a. Checking the catalyst temperature. This method is unacceptable since the catalyst temperature does not rise significantly in the case of low frequency misfire. In addition, the identification of the misfire cylinder is impossible.

b. Monitoring the oxygen sensor signal. This method also fails because a single misfire does not significantly alter the sensor output voltage. Even if using cylinder individual $\mathrm{O}_{2}$ sensors.

c. In-cylinder pressure measurement. This method is the most accurate as individual cylinder IMEP could be calculated in real time. However, the cost of fitting each cylinder with a pressure transducer is expensive.

d. Evaluation of crankshaft angular velocity fluctuations is used nowadays. This method is hampered by the load torque induced by the drive train, and torsional vibrations of the crankshaft [2].

Klenk et. al. [5] used surface vibration intensity and acoustic intensity techniques to identify noise sources radiated from a diesel engine surface. These techniques were compared with the lead wrapping technique. It is found that the both intensity techniques have advantages over the lead-wrapping approach. Klauber et. al. [6] developed a miniature sensor for detecting cylinder misfiring based on the principle of magnetostriction which can be used for on-board use. Due to magnetostriction, the field strength changes as the stress in the crankshaft changes during each cylinder firing. The output of the sensor is therefore high when any given cylinder fires and low when it misfires, permitting ready determination of misfiring. The identification of cylinder misfire by the aid of a manifold pressure observer was discussed by Shiao et. al. [7]. In the development of pressure observer, runner-by-runner intake manifold model was proposed. The nonlinear observer using this model can estimate the plenum pressure and all individual runner pressures and their subsequent flows. The estimate is then used as an indication of a faulty inlet valve, one of the possible causes of engine misfire. References [8] and [9] describe a method based on the dynamic relationship between torque and angular velocity fluctuations in a 
multi-cylinder engine. It is shown that the torque waveform can be reconstructed from the crankshaft angular velocity signal by means of this relationship, and then engine misfire can be detected. Algorithms for misfire detection based on a frequency domain analysis of the angular velocity signal are used by Lee et. al. [1] and Azzoni et. al. [10]. Experimental results confirm that the algorithms using spectral information between the engine firing frequency and the engine cycle frequency provide good correlation with IMEP, and could therefore find application in the detection of engine misfire. Azzoni et. al. [11] used signal processing to extract the information regarding IMEP or indicated torque from the angular velocity signal, and to relate it to combustion quality with sufficient accuracy to detect single misfire events.

Instead of measurements of flywheb angular velocity to detect misfires, K., Ball et. al. [2] used the measurements of the angular acceleration of the engine block to detect engine misfire. The torque was calculated from a mathematical model that relates it with the block angular acceleration. The calculated torque waveform was then used to calculate a cylinder mean effective pressure (CMEP). This was compared to the IMEP for that cylinder on a cyke-by-cycle basis to identify misfires. It was found that the method of calculation of CMEP was limited to lower engine speeds and loads.

The above summary of the different approaches for detecting engine misfire indicates that each approach has its limitations. In this paper, an investigation of engine misfire detection by the analysis of engine vibration is utilized. Although herein the measurements of engine vibration are used similar to [2], the techniques of analysis are different. Instead of calculation of torque and CMEP adopted by K., Ball et. al. [2] the frequency domain analysis and time-frequency analysis are herein. The frequency domain analysis is used to investigate the limitation of the FFT-only approach. Then acceleration signals are analyzed in time-frequency plane to overcome the limitations of the analysis FFT. The time-frequency plane is then converted to corresponding crank angle-frequency plane in order to identify the misfire cylinder according to the engine firing order.

This paper is organized as follows: i) Introduction, ii) A Mathematical model of I.C. engines combustion induced vibration, iii) Simulation of a six cylinder diesel engine combustion induced vibration and noise during firing and misfiring, iv) Time-analysis, v) Short time Fourier transform, vi) Experimental setup, vii) Test procedure, viii) Signal analysis and discussion of results and ix) Conclusions.

\section{A MATHEMATICAL MODEL OF I.C. ENGINE COMBUSTION INDUCED VIBRATION}

The predominant noise of the automotive engine lies in the frequency band from 900 to $2000 \mathrm{~Hz}$ which is determined by the vibration of various elements of the engine which thus determine the characteristics of radiated noise [12]. The engine can be considered to consist of two basic structural elements: a) the internal load-carrying structure, i.e. pistonconnecting rod-crankshaft system, and b) outer load-carrying cylinder block structure. 
Each of the elements is capable of vibration at its natural frequency if an impulsive force is applied to it and thus contributes to the characteristics of resultant noise.

The internal load carrying structure is mechanically separated from the main outer load carrying one by running clearances. A simple equivalent system of the engine thus can be developed as shown in Fig.1.a that illustrates the principle exciting forces which are responsible for the generation of vibration and noise. The outer elastic load carrying structure that provides location for the piston and crankshaft is represented as two major masses joined together by a spring and damper.

In the engine system, there are two major forces which are responsible for engine structure vibration and the emitted noise, namely unidirectional force, $\mathrm{F}$ and reversible force $Q$. The clearances in the vertical direction for the equivalent mass of piston, connecting rod and crankshaft are taken up by the unidirectional force $F$ and a linear vibratory system results as shown in Fig.1.b. Since during this period the force does not change its direction, any appreciable vibration can only be produced if there is a rapid change in the magnitude of the force. The rapid change in the magnitude is produced by the combustion in the engine cylinder. Thus the generated vibration and noise can be defined as combustion induced vibration and noise. As can be seen the gas force $F_{g}$ excites the top part of the engine structure (i.e. cylinder head) while the lower part of the structure is excited by the combined gas force and inertia force, $F_{g}+F_{i}$ [12] [13].

The equation of motion of the equivalent system is given by:

$$
m \ddot{x}+c \dot{x}+k x=F(t)
$$

Where $\mathrm{m}$ is the piston mass; $\mathrm{x}$ is the response $(\mathrm{m})$; $\mathrm{c}$ is the damping factor; $\mathrm{k}$ is the stiffness; $\dot{x}$ is the velocity and $\ddot{x}$ is the acceleration.

Since the force applied to the system is an impulsive force, the response of the system due to a unit force can be obtained according to Rao [14] as follows:

$$
x(t)=\frac{e^{-\zeta \omega_{n} t}}{m \omega_{d}} \sin \left(\omega_{d} t\right)
$$

where $\omega_{n}=\sqrt{\frac{k}{m}}$, is the natural frequency of the system.

$$
\zeta=\frac{c}{2 m \omega_{n}} \text {, is the damping factor. }
$$

$\omega_{d}=\omega_{n} \sqrt{1-\zeta^{2}}$, is the damping frequency. 
(a)

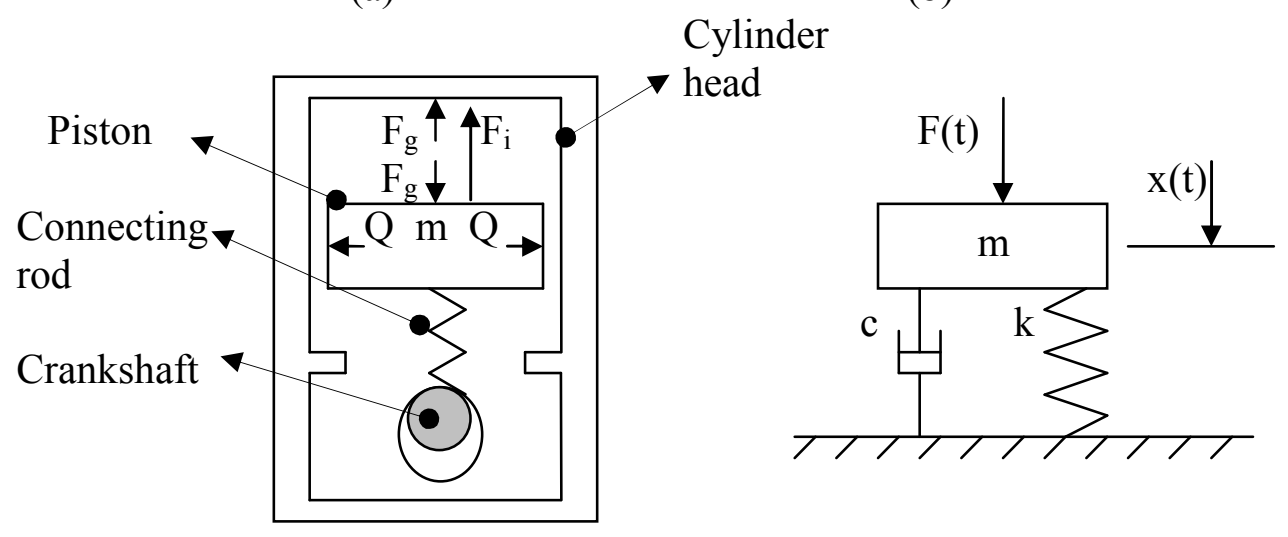

Fig.1. (a) Simple equivalent system of the engine, (b) Linear vibratory system.

\section{SIMULATION OF DIESEL ENGINE COMBUSTION INDUCED VIBRATION AND NOISE}

The engine combustion induced vibration and noise during complete firing of the all six cylinders is simulated by assumed values: $\mathrm{k}=444132198 \mathrm{~N} / \mathrm{m}, \mathrm{m}=5 \mathrm{Kg}$, and $\mathrm{c}=5920$ $\mathrm{N} . \mathrm{s} / \mathrm{m}$ in equation (2). The engine speed is assumed to be $1500 \mathrm{rpm}$. The angular velocity of the crankshaft is calculated to be $25 \mathrm{~Hz}$. The angular velocity of the four stroke engine cycle is half that of the crankshaft angular frequency, $12.5 \mathrm{~Hz}$. The time of the engine cycle, therefore is calculated to be 0.08 second. The sampling rate is chosen to correspond to half degree of crank angle rotation, therefore the engine cycle time is divided by 1440 to obtain the sampling rate of $5.555 \times 10^{-5}$ second corresponds to sampling frequency $18000 \mathrm{~Hz}$. This sampling frequency is greater than the double Nyquist frequency which is approximately $2000 \mathrm{~Hz}$ as observed from the spectrum analysis of the measured signal.

The simulated response $x(t)$ of the No. 1 cylinder of the six cylinders engine is theoretically calculated during a period of time equal to one sixth of the engine cycle time. The signal is then shifted by a phase angle $15^{\circ}$ to obtain the point of maximum pressure. Then, the acceleration signal is calculated by multiplying the displacement $x(t)$ by the square of the system natural frequency $\left(\omega_{n}{ }^{2}\right)$. With a time shift of 0.01333 second corresponding to $120^{\circ}$ phase angle, the acceleration signal of the 6 cylinders engine cycle is obtained according to the engine firing order. The time varying signal is converted to crank angle varying signal by multiplying the time by $6 n$ where $n$ is the engine speed. Then, the acceleration signal is drawn in the crank angle domain as shown in Fig.2.a.

The simulated combustion induced vibration during individual cylinder misfire is theoretically calculated too with the same engine speed and sampling frequency used for 
complete firing. The engine misfire is assumed to be occurred in the cylinder number 6 by the assumption that the fuel is cut off from it. To do that the displacement and acceleration signals during firing of the cylinder number 6 are obtained by assuming that the pressure force is extremely very small. This means that the IMEP during cylinder misfire tends to zero. With the same engine speed and sampling frequency the response $x(t)$ and the acceleration of the misfired cylinder are obtained during a period of time 0.01333 second. The acceleration signal is shifted by a phase angle $360^{\circ}$ to be for the cylinder number 6 . By arranging the signals of completely fired cylinders $1,5,3,2$, and 4 with the completely misfired cylinder No.6 along the engine cycle time $(0.08 \mathrm{~s})$, the acceleration signal of the misfired engine is drawn in thecrank angle $d$ omain as shown in Fig.2.b.

(a)

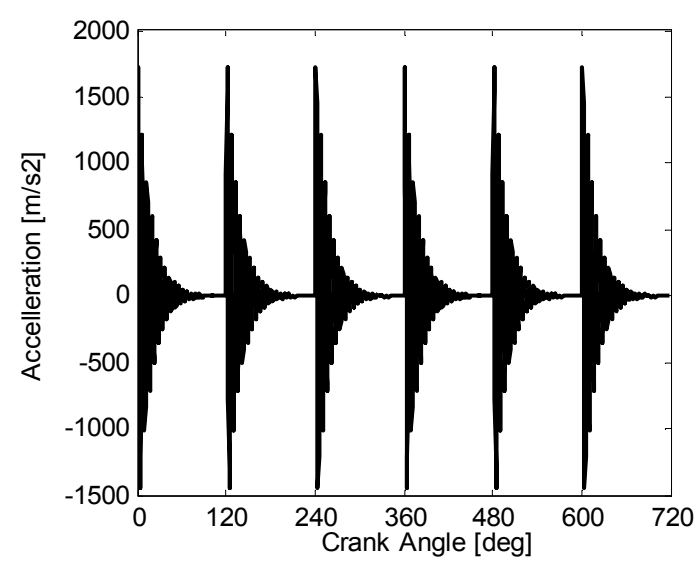

Fig.2 Simulated vibration signals, (a) During firing, (b) During misfiring (b)

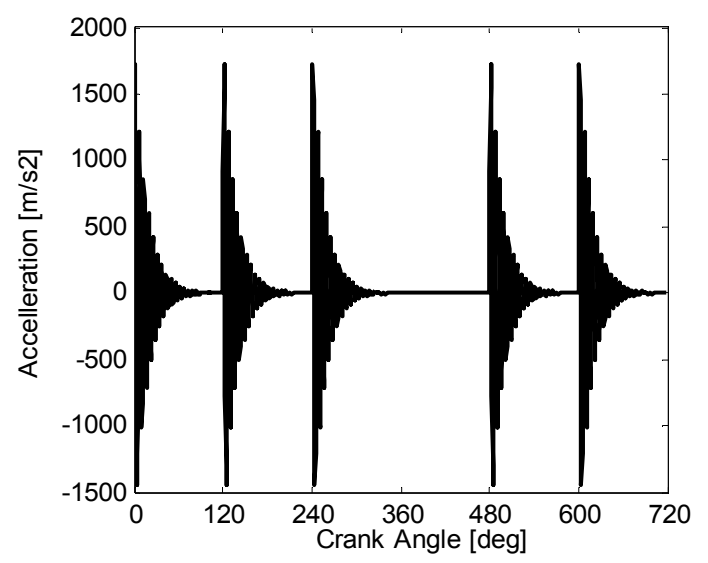

\section{TIME-FREQUENCY ANALYSIS}

Even after all the advantages that have been offered by signal processing and its applications, the Fourier transform is still the most powerful tool. However, the use of fast Fourier transform (FFT) is still limited [15]. The major limitation comes from its won definition:

$$
X(f)=\int_{-\infty}^{\infty} x(t) e^{-j 2 \pi f t} d t
$$

where the time variable $t$ is lost as a dummy variable in the integration. In other words, the integration occurs over entire time, from minus infinity to plus infinity.

An alternative tool is required for instantaneous Fourier transform (call it $X(\tau, f)$ ) of the signal $x(t)$. The class of the basis functions now contains two parameters, time $\tau$ and frequency $f$ so one can determine the instantaneous frequency spectrum which is called time-frequency analysis. In the time-frequency expansion, the basis signal $e_{\tau, f}(t)$ is windowed around time $t=\tau$.

For a continuous time signal $x(t)$, the time-frequency expansion can be given by a discrete or continuous expansions in terms of new basis functions $e_{p, r}$ and $e_{\tau, f}$ as follows: 


$$
\begin{aligned}
& x(t)=\sum_{p, r} X[p, r] e_{p, r}(t) \leftrightarrow X[p, r]=\int x(t) \widetilde{e}_{p, r}^{*}(t) d t \\
& x(t)=\int X(\tau, f) e_{\tau, f}(t) d \tau d f \leftrightarrow X(\tau, f)=\int x(t) \widetilde{e}_{\tau, f}^{*}(t) d t
\end{aligned}
$$

As in the Fourier transform, the expressions on the right define transforms, while those in the left define inverse transforms.

\section{SHORT TIME FOURIER TRANSFORM}

The short time Fourier transform (STFT) presents a signal $x(t)$ in a time-frequency expansion. Windowing a signal around a time $\tau$ and then computing the Fourier transform, is the easiest way to determine the local behavior of a signal. In this way, the short time Fourier transform of a signal is defined as:

$$
X(\tau, f)=\operatorname{STFT}\{x(t)\}=F T\{x(t) w(t-\tau)\}
$$

where $w(t-\tau)$ is a window and $x(t)$ is the signalwhich is centered around the time variable $\tau$. Notice the need to distinguish between two time variables: the time variable of the signal $\mathrm{x}(\mathrm{t})$ and the time variable of the time frequency expansion $\mathrm{X}(\mathrm{t}-\tau)$.

Expanding the Fourier transform gives [15]:

$$
X(\tau, f)=\int_{-\infty}^{\infty} x(t) w(t-\tau) e^{-j 2 \pi f t} d t
$$

\section{EXPERIMENTAL SETUP}

In this paper the tests were carried out on a six cylinder direct injection diesel engine Mercedes 352 natural aspirated with $120 \mathrm{HP}$ power at $2800 \mathrm{rpm}$. Appendix (A) shows the more detailed engine specifications. The measurement of engine speed and triggering are encountered by a shaft encoder of type GI 328r. The in-cylinder pressure of the cylinder No. 6 is measured by a Kistler $601 \mathrm{~A}$ piezoelectric pressure transducer. The engine vibration is measured by a Brüel \& Kjaer accelerometer of type 4367 which is fixed with a magnet on the left side of the cylinder head. Brüel \& Kjaer conditioning amplifier of type 2626 and Kistler 5010B charge amplifier are used for conditioning of vibration and pressure signals respectively.

A National Instrument PCI-MIO-16E-1 card and LabVIEW 7.1 software are used for data acquisition. A P-III Dell computer with $933 \mathrm{MHz}$ processor, $128 \mathrm{MB}$ RAM and $80 \mathrm{~GB}$ HD is used. The 36000 samples of data are acquired at speed of $1500 \mathrm{rpm}$ at no load with sampling frequency $18000 \mathrm{~Hz}$. 


\section{TEST PROCEDURE}

a. During normal operation the engine is run at $1500 \mathrm{rpm}$ without load, then the incylinder pressure signal and the vibration signal are acquired simultaneously according to encoder digital triggering.

b. The fuel is completely cut of the cylinder No. 6, then the engine is run at $1500 \mathrm{rpm}$ and the in-cylinder pressure and vibration signals are acquired. The measurements during engine misfire are carried out with the same speed as that during fire in order to achieve better comparison at the same operating conditions.

\section{SIGNAL ANALYSIS AND DISCUSSION OF RESULTS}

The measured in cylinder pressure signals during firing and misfiring of the cylinder No. 6 are drawn in crank angle-frequency domain as shown in Fig.3. During cylinder misfire the in-cylinder pressure is exactly the compression pressure. If the measured in-cylinder pressure during power stroke is coincided with the compression pressure this indicates a misfired cylinder. If the fire pressure curve is greater than that of compression one this indicates that the cylinder is firing.

It is easy to distinguish between the simulated acceleration signals during engine firing and misfiring, because the signals have no noise, see Fig.2. It seams difficult to distinguish between the measured acceleration signals during engine firing and misfiring which are shown in Fig.4.a and Fig.4.b respectively. Therefore, the signals are analyzed by FFT in order to detect cylinder misfire. The power spectrum analysis the power of the simulated vibration signal during firing is greater than that during misfiring as shown in Fig.4.a and Fig.4.b respectively. Similarly, that occurs for the measured signal as shown in Fig.8.a and Fig.8.b during firing and misfiring respectively. As shown in Fig.8.b, at low frequencies the power during misfiring is greater than that during firing, see Fig.8.a but these low frequencies are out of the combustion frequency band which is about $900-2500 \mathrm{~Hz}$.

The decrease of the signal power in Fig.4.b and Fig.8.b indicates the engine abnormality, but this not an indication of engine misfire. Even if it is assumed that this is indication of engine misfire, the question is that which cylinder is misfiring. The combustion frequency for each cylinder which indicates firing can not be obtained from the FFT analysis. The above question has leaded the authors to investigate time-frequency analysis for misfire detection. This may solve the problem, because one can observe the frequency at any time during signal progress. The simulated and measured vibration signals are analyzed in time-frequency plane and the time is converted to crank angle by multiplying the time by $6 n$ where $n$ is the engine speed. In the crank angle-frequency contour plot, as shown in Fig.5.a and Fig.5.b, the rows represent the combustion frequency and the columns represent the cylinder order. In Fig.5.a, for simulated signals, all the six frequencies of the six cylinders appear, but in Fig.5.b the frequency of the cylinder No. 6 is disappeared on the contour plot which indicates misfire of cylinder No. 6. Similarly, the measured signals during firing and misfiring are represented in crank angle-frequency plane as shown in Fig.9.a and Fig.9.b. It is obviously shown in Fig.9.a that a column of frequencies appears corresponding to each cylinder. This indicates that all the cylinders are fired. In Fig.9.b the column No. 4 that related to cylinder No. 6 is disappeared on the crank angle-frequency plane. This attributes to misfire of that cylinder. 
The crank angle, the frequency and the magnitude of the signal are plot in a three dimensional plot for better certainty of misfire detection. The magnitude corresponding to each cylinder well appears as shown in Fig.6.a for the simulated fired engine signal and disappears for the misfired signal as shown in Fig.6.b. Similarly, that occurred for the measured signal as shown in Fig.10.a and Fig.10.b for fired and misfired engine respectively.

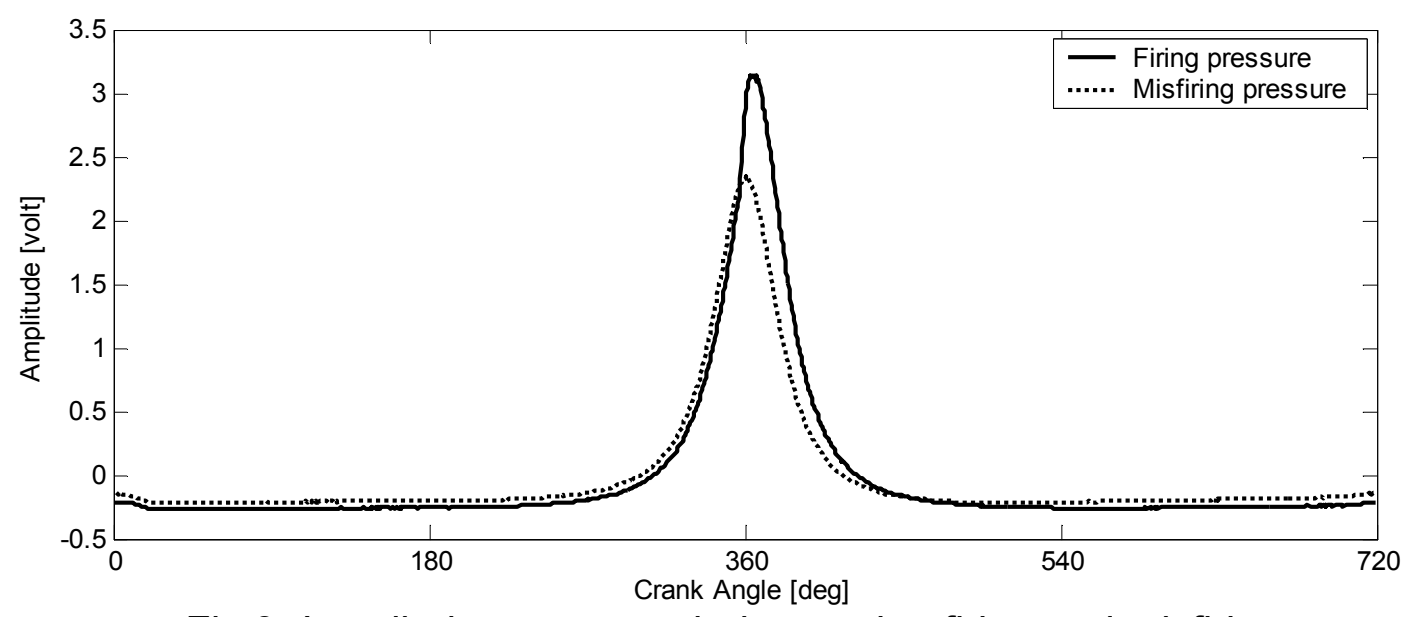

Fig.3. In-cylinder pressure during engine firing and misfiring.

(a)

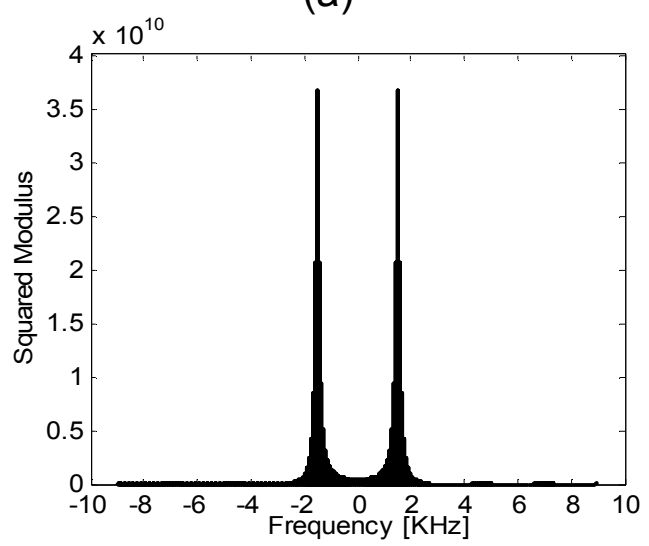

(b)

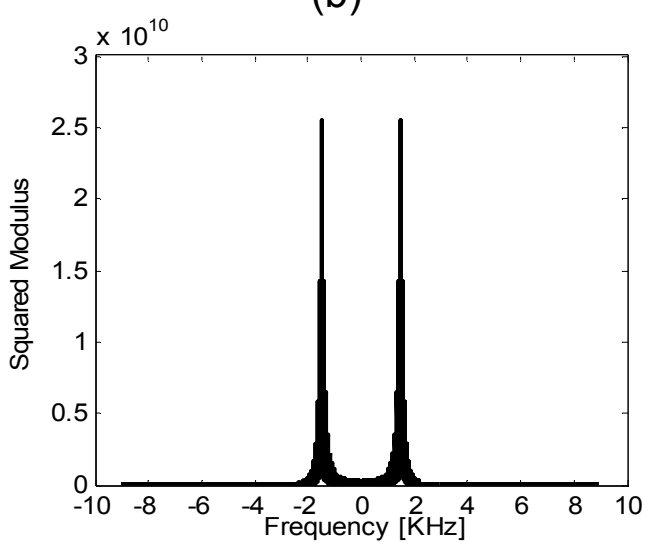

Fig.4. Energy spectrum of the simulated signals, (a) During firing, (b) During misfiring. 

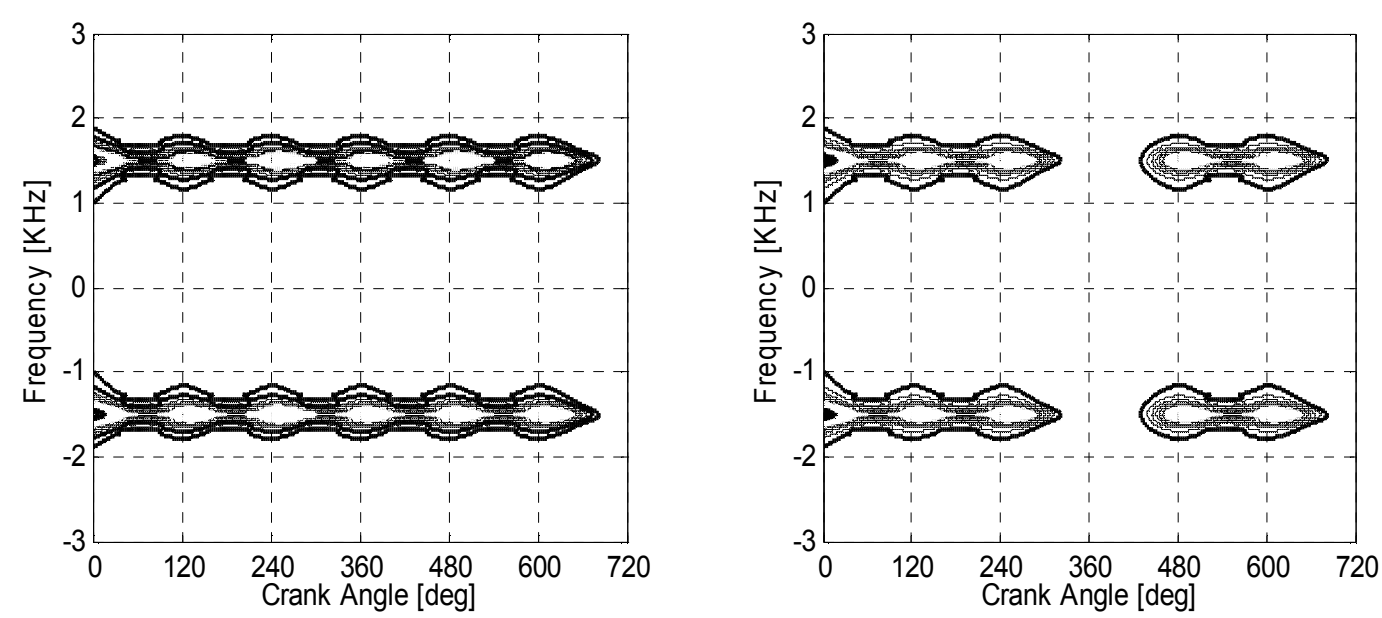

Fig.5. Contour plot of the simulated signals in crank angle-frequency plane, (a) During firing, (b) During misfiring. 
(a)

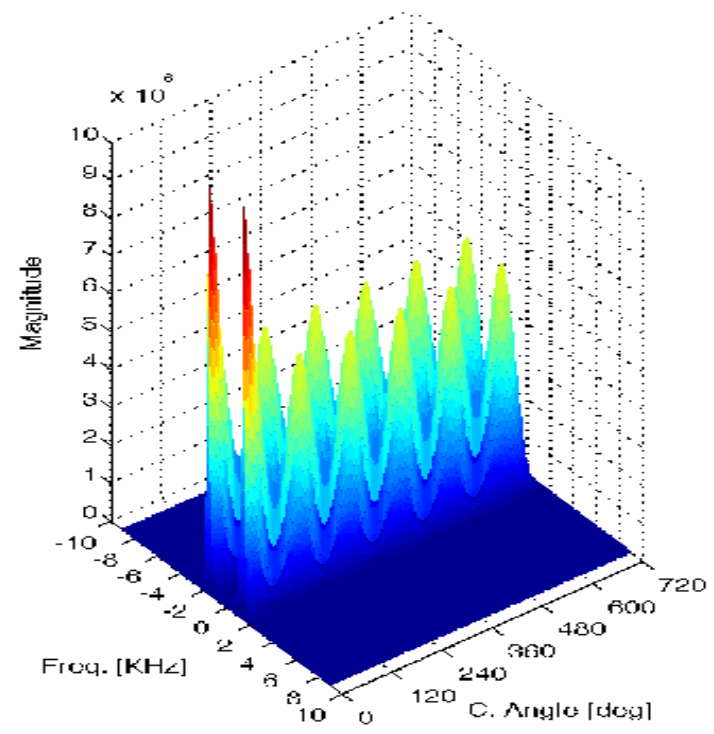

(b)

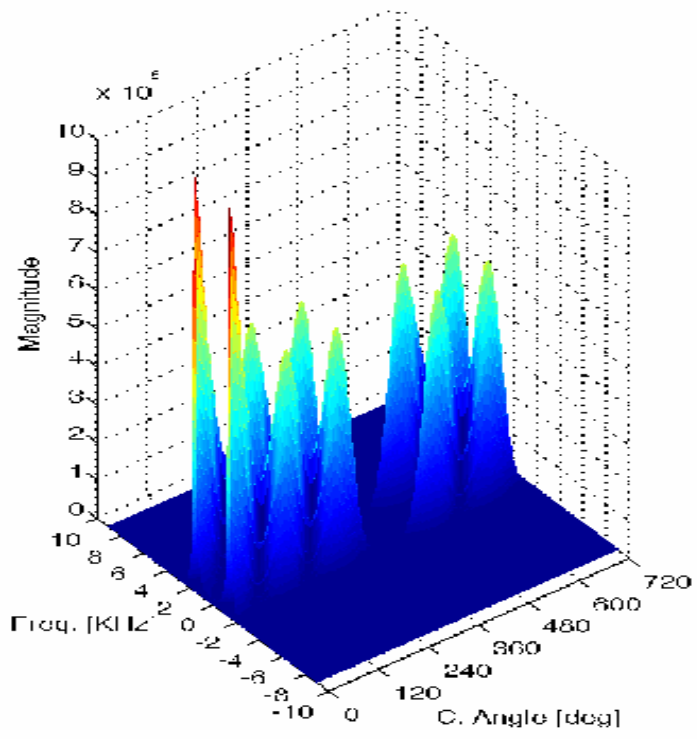

Fig.6. Three dimensional graph of simulated signals, (a) During firing, (b) During misfiring.

(a)

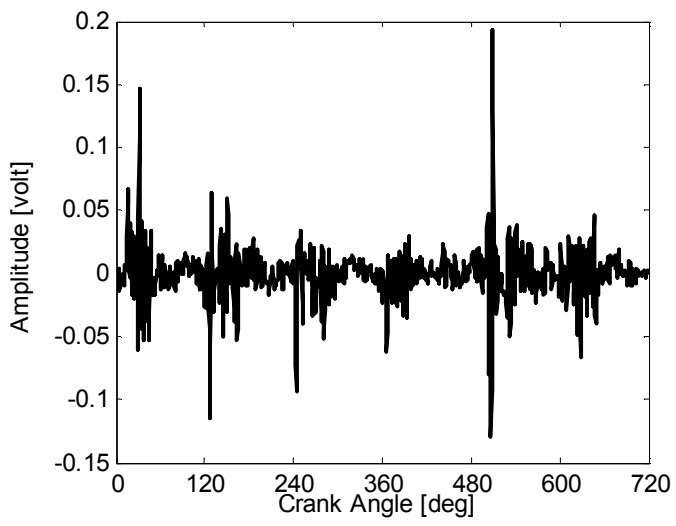

(b)

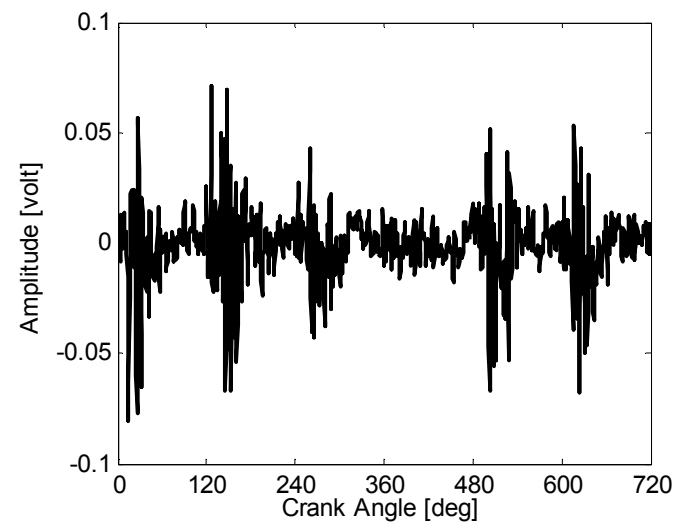

Fig.7. Measured vibration signals, (a) During firing, (b) During misfiring. 
(a)

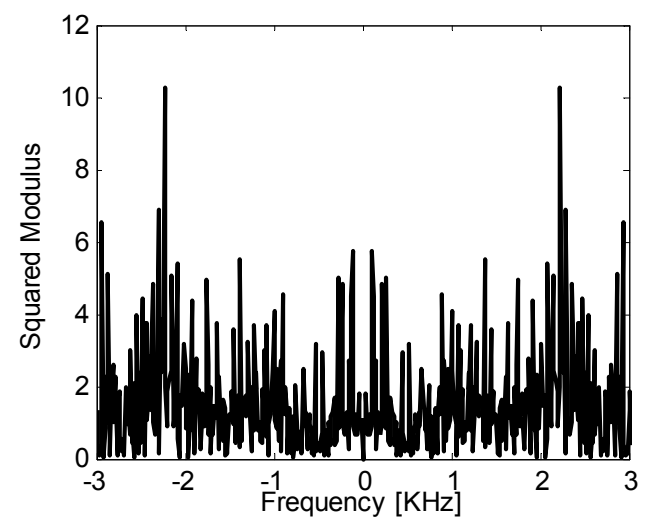

(b)

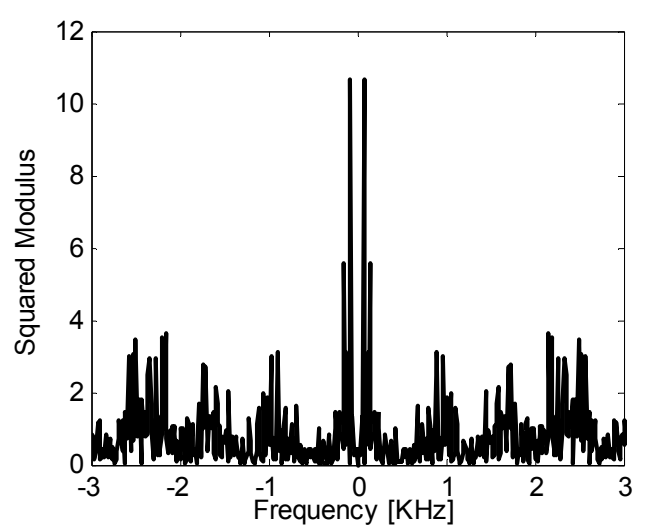

Fig.8. Energy spectrum of the measured signals, (a) During firing, (b) During misfiring.

(a)

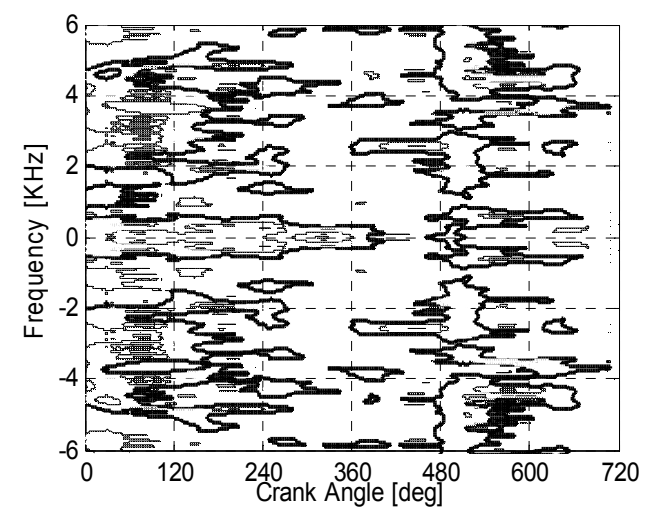

(b)

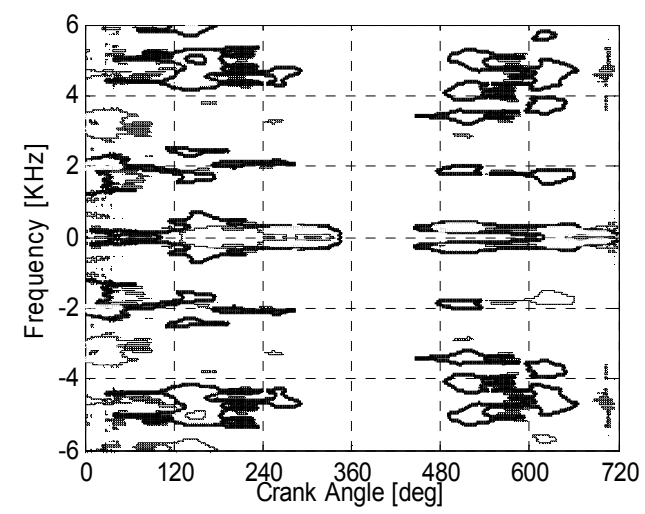

Fig.9. Contour plot of the measured signals in crank angle-frequency plane, (a) During firing, (b) During misfiring. 
(a)

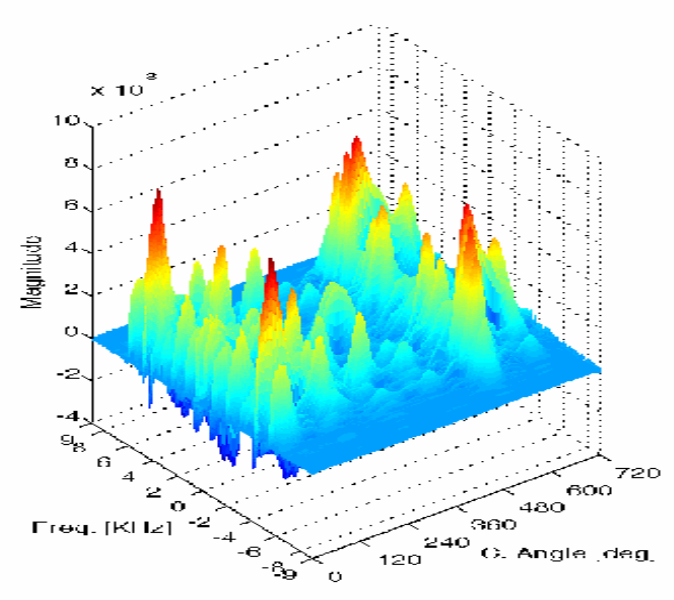

(b)

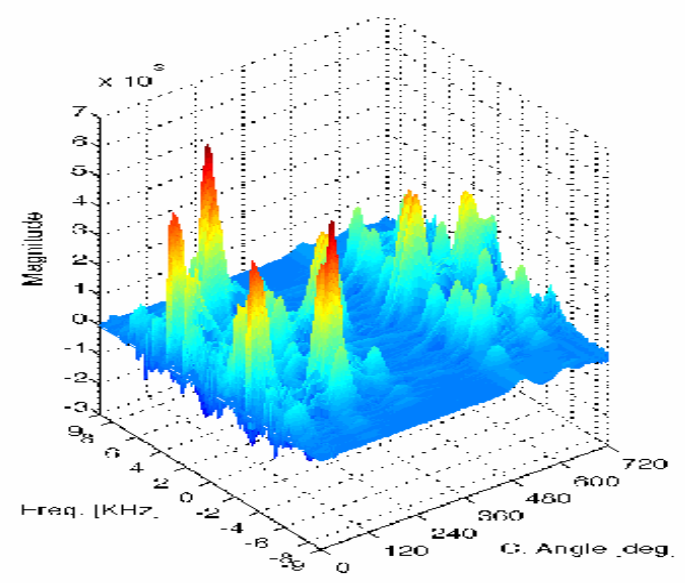

Fig.10. Three dimensional graph of measured signals, (a) During firing, (b) During misfiring.

\section{COCLUSIONS}

In this paper, engine misfire detection is investigated using FFT and time-frequency analysis of the simulated and measured engine vibration signals. The analysis of the simulated and measured vibration signals during firing and misfiring show that engine operation abnormality can be detected by the FFT, but it is difficult to distinguish which cylinder is misfired.

The results show that the engine misfire can be detected by the time-frequency analysis. The misfire of a specific cylinder can be detected by contours in the crank angle-frequency plane and the three dimensional graph.

It may be very difficult for an observer to distinguish a misfired cylinder by naked eye in real-time from the displayed contour and three dimensional graph.

Misfire detection in real-time needs the knowledge of the frequency and the magnitude of the engine vibration signal for each cylinder during combustion. The frequency and magnitude of engine vibration signal for a completely fired cylinder should be obtained from static time-frequency analysis of collected data as references. Then, misfire in can be detected by comparing the calculated frequency and magnitude of each cylinder during engine running with the reference ones. In order to specify a cylinder, the cylinders should 
be counted according to their firing order, since the sampling trigger begins when the piston at the TDC during suction stroke of the cylinder No. 1. The results of comparison can be used as feedbacks for controlling the misfire by isolating the misfired cylinder.

\section{REFERENCES}

1. Lee., D. and Giorgio Rizzoni, "Detection of Partial Misfire in IC Engines using a Measurement of Crankshaft Angular Velocity", SAE paper 951070, 1995.

2. K., Ball Jeffrey, Martin J. Bowe, C. Richard Stone and Peter D. McFadden, "Torque Estimation and Misfire Detection using Block Angular Acceleration", SAE Technical paper 2000-01-0560, 2000.

3. Heywood, J. B., Internal Combustion Engine Fundamentals, McGraw-Hill Book Company, New York, $4^{\text {th }}$ Edition, 2004.

4. Martin, J. K., Steven L. Plee, Donald J. and Remboski Jr., "Burn Models and Prior Cycle Effects on Cyclic Variations in Lean-Burn Spark-Ignition Engine Combustion", SAE paper 880201, 1988.

5. Klenk, M., Winfred Moser, Werner Mueller and Wolfgang Wimmer, "Misfire Detection by Evaluating Crankshaft Speed - A Means to Comply with OBDII", SAE paper 930399, 1993.

6. Klauber, R. D., Erik B. Vigmostad, Jon Van Gerpen, Delmar Van Meter, Frederick P. Sprague and Fred Reiter, Jr., "Miniature Magnetostrictive Misfire Sensor", SAE paper 920236, 1992.

7. Shiao, Y., and John J. Moskwa, "Fault Identification in Engine Misfire using a Runnerby-Runner Intake Manifold Pressure Observer", SAE paper 960327, 1996.

8. Rizzoni, G., "Diagnosis of Individual Cylinder Misfire by Signature Analysis of Crankshaft Speed Fluctuations", SAE paper 890884, 1989.

9. Ribbens, W. B., and J. Park, "Road Test Results of an I-C Engine Misfire Detection System", SAE paper 930398, 1993.

10. Azzoni, P., G. Cantoni, G. Minelli, D. Moro, Giorgio Rizzoni, M. Ceccarani and S. Mazzetti, "Measurement of Engine Misfire in the Lamborghini $533 \mathrm{~V}-12$ Engine Using Crankshaft Speed Fluctuations", SAE paper 950837, 1995.

11. Azzoni, P. M., Davide Moro, Carlo Maria Porceddu-Cilione and Giorgio Rizzoni, "Misfire Detection in a High-Performance Engine by the Principal Component Analysis Approach", SAE paper 960622, 1996.

12. Ewins, D. J., Model Testing: theory, practice and application, $2^{\text {nd }}$ edition, Research Studies Press, 2000.

13. McConnell, K. G., Vibration Testing: Theory and Practice, $1^{\text {st }}$ edition, John Willey, 1995.

14. Rao, S. S., Mechanical Vibrations, $4^{\text {th }}$ edition, Pearson, 2004.

15. Roberto Cristi, Modern Digital Signal Processing, $1^{\text {st }}$ edition, Thomson, 2004. 
Appendix A

Engine Specifications

Model

No. of strokes

Mercedes 352 natural aspirated diesel engine

No. of cylinders

4

Arranging

6

Cooling

In-line

Bore

Water

Stroke

Combustion chamber

$97 \mathrm{~mm}$

$128 \mathrm{~mm}$

Open type, direct injection

Cam shaft

On side

Speed range

Maximum power

Minimum torque

Start of fuel injection

800-2800 rpm

$120 \mathrm{HP}$ at $2800 \mathrm{rpm}$

275 N.m at $1600 \mathrm{rpm}$

$23^{\circ} \mathrm{CA}$ BTDC

Firing order

1536241 